\title{
THE GENETIC AND ENVIRONMENTAL BASIS OF PUPAL COLOUR DIMORPHISM IN PAPILIO ZELICAON (LEPIDOPTERA: PAPILIONIDAE)
}

\author{
STEVEN R. SIMS \\ University of Florida Agricultural Research and Education Center, \\ 18905 S.W. 280th Street, Homestead, Florida 33031, USA
}

Received 5.xi.82

\section{SUMMARY}

\begin{abstract}
The genetic and environmental basis of brown and green pupal colour dimorphism in the butterfly Papilio zelicaon was studied using univoltine, multivoltine, and selected low-diapause populations. The propensity for formation of brown pupae and the positive correlation between brown pupae and diapause show both inter- and intrapopulation variability. Reciprocal hybrids had colour frequencies and magnitude of the pupal colour-diapause correlation intermediate between parental population values with evidence for maternal effects in the latter. Colour frequencies among individual broods were normally distributed. One generation of selection increased incidence of green pupae and was most effective at a high selection differential. Selection results plus a heritability determination indicated that pupal colour dimorphism in P. zelicaon is a threshold trait with quantitative genetic variation. Short days and cool temperatures induced mostly diapause brown pupae irrespective of pupation substrate whereas long days and warm temperatures facilitated continuous development and cryptic colour matching of pupae to their substrate.
\end{abstract}

\section{INTRODUCTION}

The environmental basis for pupal colour dimorphism (typically green or brown) has received considerable attention, particularly among the Pieridae and Papilionidae (see Smith 1978, 1980 for references). Among papilionids with dimorphism, a variety of environmental stimuli, often interacting in a complex manner, influence final pupal colouration. These stimuli include photoperiod (Ishizaki and Kato, 1956; West et al., 1972; Smith, 1978), pupation substrate diameter (Clarke and Sheppard 1972; Sims and Shapiro, 1983), relative humidity (Ishizaki and Kato, 1956; Smith, 1978; Honda, 1981), foodplant odor (Honda, 1979), wavelength of light experienced by the prepupa (Wiklund, 1972), and the colour and texture of the pupation substrate (Smith, 1978; Hazel and West, 1979, Sims and Shapiro, 1983).

The genetic control of dimorphism is less well understood. Ohnishi and Hidaka (1956) found little evidence for genetic determination of pupation site or pupal colour in Papilio protenor demetrius $\mathrm{Cr}$. and Papilio xuthus L. Crosses between Papilio machaon L. emerging from pupae of the same colour (green or brown) indicated that a complex gene-environment interaction affects pupal colour (Clarke, 1952). Recent work shows that substantial genetic variation can influence both behavioural and physiological aspects of pupal dimorphism. Clarke and Sheppard (1972) found genetic variation in choice of pupation site in Papilio polytes L. and modified this behaviour through selection. Other examples of variation in pupation site selection behaviour in Papilio polyxenes Fabricius and Battus philenor (L.) (West 
and Hazel, 1979; Sims and Shapiro, 1983) indicate that this trait can be modified by photoperiod and show inter- and intrapopulation variation. Using standardized rearing and pupation substrate conditions, Hazel (1977) observed significant variation in proportions of green and brown pupae among broods of $P$. polyxenes, and successfully selected for increased incidence of both green and brown pupae. He concluded that dimorphism is a threshold trait with quantitative genetic variation underlying the two phenotypes. Similar conclusions have been reached regarding the control of integument colouration in the Orthopteran families, Gryllidae and Acrididae (Fuzeau-Braesch, 1960; Nel, 1968).

The physiology of dimorphism in Papilio xuthus, Papilio polytes, and Papilio demoleus L. is controlled by an endocrine mechanism in the prepupal brain. When sufficient environmental stimulation is received, hormones are produced which result in brown coloured pupae (Hidaka, $1961 a, b$; Smith, 1978). This mechanism makes it convenient to regard individual variation in pupal dimorphism as a continuum of variation in the amount of stimulation necessary for hormone release, i.e., "sensitivity" (Hazel, 1977). To facilitate analysis, "sensitivity" and other presumed quantitative genetic traits with all-or-none phenotypic effects are considered to follow a normal distribution. Under given environmental conditions, a proportion of individuals will have "sensitivities" exceeding the "threshold" of expression and will thus be brown (Falconer, 1960, 1965). The most sensitive individuals need little stimulation to attain brown colouration whereas the least sensitive individuals are green even under conditions strongly promoting brown colouration. Although the endocrine release-brown pupa mechanism seems typical for papilionids and is used as a working hypothesis for Papilio zelicaon Lucas in this paper, other Lepidoptera such as the Pieridae may show the opposite reaction: hormone secretion results in production of green pupae (Smith, 1980).

This paper investigates the effects of rearing conditions and substrate qualities on dimorphic pupal colouration in $P$. zelicaon. The genetic basis for the dimorphism is analyzed by determining sensitivity of individual female broods and populations, analyzing the correlation betweeen pupal colour and diapause, and through selection and hybridization experiments.

\section{MAterials AND Methods}

$P$. zelicaon were obtained from two multivoltine (M) California populations; Suisun Marsh, Solano Co., el. $<10 \mathrm{~m}$, and Rancho Cordova, Sacramento Co., el. $<30 \mathrm{~m}$, and three univoltine (U) populations; Butts Canyon, Napa Co., el. 500 m, Foresthill, Placer Co., el. 750 m, and Donner Pass, Placer Co., el. $2100 \mathrm{~m}$. A low diapause strain (S) having a reduced critical photophase $(\mathrm{CP}=$ photophase inducing 50 per cent diapause response) and lowered diapause intensity (chilling duration necessary for diapause termination) was obtained after five generations of mass selection using previously described procedures (Sims, 1980).

Laboratory matings (of $P$. zelicaon) were obtained by the hand-pairing technique of Clarke and Sheppard (1956). Adult females oviposited on Foeniculum vulgare Mill. in 2-liter containers under a LD 14:10 (14 hrs light: $10 \mathrm{hrs}$ dark) photoperiod at either $23.5^{\circ} \mathrm{C}$ or $29.5^{\circ} \mathrm{C}$. Larvae were reared on $F$. vulgare in wooden-frame $(46 \mathrm{~cm}$ side) white nylon mesh cages 
or 2-liter white cardboard containers within environmental chambers at constant $\left( \pm 1^{\circ} \mathrm{C}\right)$ temperature(s), various photoperiods, and $40-70$ per cent relative humidity. Pupae unemerged after 30 days under the rearing conditions were judged to be in diapause (Sims, 1980). Pupae were scored for colour (brown or green), diapause, and pupation substrate (3-6 mm wide green twigs of the host-plant, white cage walls/netting, or $18 \mathrm{~mm}$ tan wood cage frame).

The genetic basis of dimorphism was studied using LD $14: 10,23 \cdot 5^{\circ} \mathrm{C}$ rearing and pupation conditions. Only individuals pupating on white netting or cardboard were scored for pupal colour. Three experimental approaches were used in the genetic analysis. First, interbrood variation in pupal colour proportions was examined using wild-collected $(\mathrm{U})(n=11)$ and $\mathrm{M}(n=26)$ and laboratory $(S)(n=14)$ females. To stabilize the variance, the percentage of brown pupae in each brood was arcsine transformed (FreemanTukey transformation for $n \leqq 50$ (Mosteller and Youtz (1961)) and the transformed data were tested for goodness of fit compared to a normal distribution using the Kolmogorov-Smirnov test (Sokal and Rohlf, 1969).

Second, reciprocal hybrids between (U) and (S) were obtained and the colour response of hybrid pupae was compared to both the parental and the $(\mathrm{M})$ lines. The percentages of brown pupae, brown pupae diapausing, and green pupae diapausing in each brood were arcsine transformed and crosses analyzed using ANOVA and Duncan's multiple range test for the significance of differences among means (Sokal and Rohlf, 1969).

Third, a single generation of selection was performed by mating (S) adults emerging from pupae of the same colour and scoring the magnitude and direction of the resulting pupal colour response. Hybrid colour crosses (i.e., brown $\times$ green) were also made. The midparent value (mean per cent brown pupae within the broods from which the parents originated) was compared to per cent brown pupae in the progeny using a G-test (Sokal and Rohlf, 1969). An estimate of heritability for production of green pupae was calculated in the manner presented by Falconer (1965) for analysis of threshold traits having presumed quantitative genetic variation.

This study considered photoperiod, temperature, and characteristics of the pupation substrate as environmental stimuli having potential effects on pupal colouration. Larvae were reared under five photoperiod/temperature combinations: LD $12: 12,13: 11$, and $14: 10$ at $23 \cdot 5^{\circ} \mathrm{C}$, and LD $12: 12$ and $18: 6$ at $29.5^{\circ} \mathrm{C}$. Within each rearing condition, larvae pupated upon either 3-6 mm green twigs of the foodplant, white netting, or $\tan (18 \mathrm{~mm}$ wide) wood frame. Differences in percentage brown and green pupae on netting and wood were not significant, allowing these groups to be combined for comparison with the green twig group in the statistical analysis.

\section{Results}

\section{(i) Genetic basis of pupal colour dimorphism}

Fig. 1 shows the frequency distributions of transformed percent brown pupae in broods of individual females from the $(\mathrm{U}),(\mathrm{S})$, and $(\mathrm{M})$ populations. All three are statistically similar to a normal distribution (Kolmogorov-Smirnov test, $p>0 \cdot 20$ ) although (U) and (M) appear skewed to the right. The apparent distinctiveness of the $(\mathrm{U})$ distribution is supported 


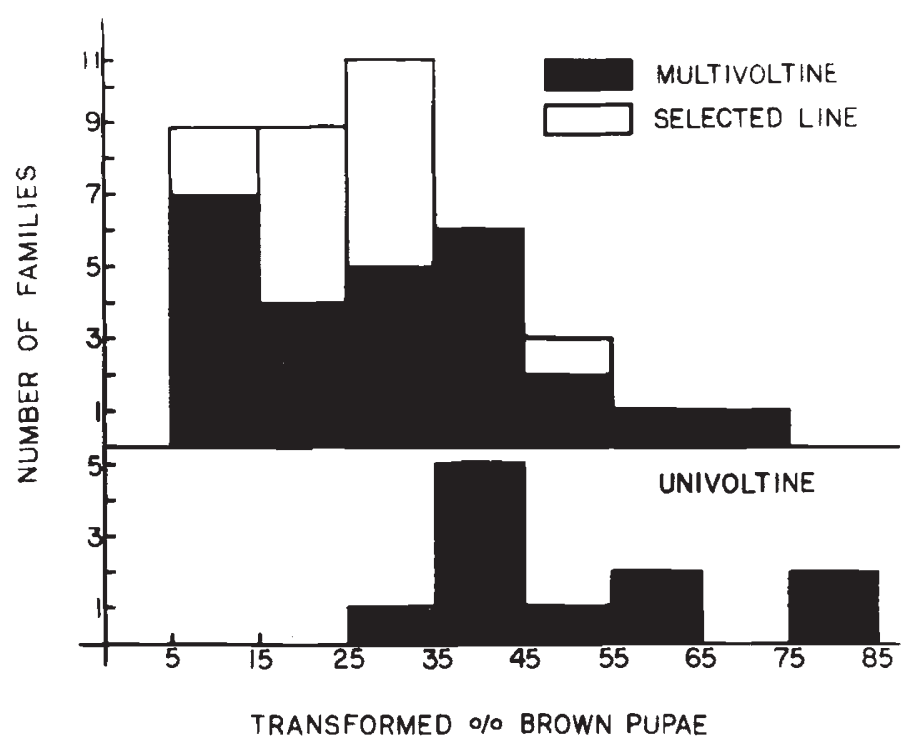

FIG. 1. Distribution of the proportion of brown pupae among broods of Papilio zelicaon.

by data in table 1 showing that $(\mathrm{U})$ females produce significantly more brown, diapause brown, and diapause green pupae than either $(\mathbf{M})$ or $(\mathbf{S})$ females. Reciprocal crosses made between (U) and (S) populations produced hybrids with percentages of brown, diapause brown, and diapause green pupae intermediate to parental values (table 1).

TABLE 1

Percent brown pupae and diapause in broods of Papilio zelicaon reared at $L D 14: 10,23 \cdot 5^{\circ} \mathrm{C}$. Pupae formed on white netting and white cardboard cage walls. Means followed by a different letter are significantly different $(D M R$ test, $p<0.05)$

\begin{tabular}{|c|c|c|c|c|c|}
\hline $\begin{array}{l}\text { Population/ } \\
\text { strain }\end{array}$ & $\begin{array}{l}\text { Number } \\
\text { broods }\end{array}$ & $\begin{array}{c}\text { Total } \\
\text { sample }\end{array}$ & $\begin{array}{c}\text { Brown } \\
\text { pupae }(\%)\end{array}$ & $\begin{array}{c}\text { Diapause } \\
\text { brown }(\%)\end{array}$ & $\begin{array}{l}\text { Diapause } \\
\text { green }(\%)\end{array}$ \\
\hline Univoltine (U) & 11 & 356 & $55 \cdot 3 \mathrm{a}$ & $85 \cdot 5 \mathrm{a}$ & $35 \cdot 3 \mathrm{a}$ \\
\hline U + × $\sigma^{\circ}$ & 4 & 147 & $30.6 \mathrm{~b}$ & $79.7 \mathrm{ab}$ & 29.7 a \\
\hline $\mathrm{S}+\times \mathrm{U} \sigma$ & 13 & 279 & $25 \cdot 1 \mathrm{~b}$ & $46 \cdot 3 \mathrm{~b}$ & $7 \cdot 5 \mathrm{~b}$ \\
\hline Low diapause (S) & 14 & 365 & $18 \cdot 6 \mathrm{~b}$ & $38.3 \mathrm{~b}$ & $3 \cdot 2 b$ \\
\hline Multivoltine (M) & 26 & 625 & $32 \cdot 0 \mathrm{~b}$ & $66 \cdot 1 \mathrm{~b}$ & $9 \cdot 0 \mathrm{~b}$ \\
\hline
\end{tabular}

Midparent and progeny values for the percentage of brown pupae produced in 10 green $\times$ green, 7 green $\times$ brown, and 1 brown $\times$ brown cross are shown in table 2 . In 7 of 10 green $\times$ green and all remaining crosses, the progeny brood had a lower percentage of brown pupae than the midparent value. Generally the increase in green pupae among progeny seems related to the selection differential (i.e., deviation from the (S) population mean) of green pupae in the parents. Among broods having midparent values of green pupae $\leqq 56$ per cent, $6 / 8$ had a significant increase in green pupae (table 2 ). The only significant increase in brown pupae involved a green $\times$ green cross with a 0 per cent brown midparent 
TABLE 2

First generation selection response, direction of colour increase, and $G$-test of the response to selection; $\boldsymbol{S}$ line

\begin{tabular}{|c|c|c|c|c|c|c|}
\hline \multirow[b]{2}{*}{ Pairings } & \multicolumn{2}{|c|}{ Midparent values } & \multicolumn{2}{|c|}{ Progeny values } & \multirow[b]{2}{*}{ Direction } & \multirow[b]{2}{*}{ G-test } \\
\hline & $\begin{array}{c}\text { Percentage } \\
\text { brown }\end{array}$ & $\begin{array}{l}\text { Sample } \\
\text { size }\end{array}$ & $\begin{array}{l}\text { Percentage } \\
\text { brown }\end{array}$ & $\begin{array}{l}\text { Sample } \\
\text { size }\end{array}$ & & \\
\hline \multicolumn{7}{|c|}{ A. Green $\times$ Green pupae $\left(q \times \delta^{\prime}\right)$} \\
\hline 1. & $47 \cdot 5$ & 85 & $21 \cdot 7$ & 23 & Green & $p<0.05$ \\
\hline 2. & $47 \cdot 5$ & 85 & $20 \cdot 0$ & 10 & Green & ns \\
\hline 3. & $47 \cdot 5$ & 85 & 0.0 & 9 & Green & $p<0.01$ \\
\hline 4. & $41 \cdot 4$ & 29 & $20 \cdot 0$ & 10 & Green & ns \\
\hline 5. & $28 \cdot 8$ & 28 & $0 \cdot 0$ & 8 & Green & ns \\
\hline 6. & $27 \cdot 9$ & 38 & $5 \cdot 0$ & 20 & Green & ns \\
\hline 7. & $22 \cdot 1$ & 28 & 0.0 & 8 & Green & ns \\
\hline 8. & $15 \cdot 0$ & 25 & $18 \cdot 2$ & 11 & Brown & ns \\
\hline 9. & $5 \cdot 0$ & 20 & $22 \cdot 2$ & 9 & Brown & ns \\
\hline 10. & $0 \cdot 0$ & 21 & $23 \cdot 1$ & 26 & Brown & $p<0.001$ \\
\hline \multicolumn{7}{|c|}{ B. Green $\times$ Brown pupae } \\
\hline 11. & $70 \cdot 7$ & 38 & $11 \cdot 5$ & 26 & Green & $p<0.001$ \\
\hline 12.* & $60 \cdot 0$ & 65 & $20 \cdot 0$ & 20 & Green & $p<0.01$ \\
\hline 13.* & $53 \cdot 6$ & 56 & $27 \cdot 3$ & 11 & Green & ns \\
\hline 14. & $43 \cdot 8$ & 55 & $27 \cdot 3$ & 33 & Green & $p<0.001$ \\
\hline 15. & $28 \cdot 8$ & 21 & $19 \cdot 2$ & 26 & Green & ns \\
\hline 16. & $15 \cdot 8$ & 31 & 0.0 & 13 & Green & ns \\
\hline 17. & $10 \cdot 0$ & 18 & $4 \cdot 8$ & 21 & Green & ns \\
\hline \multicolumn{7}{|c|}{ C. Brown $\times$ Brown pupae } \\
\hline 18. & $47 \cdot 5$ & 85 & $18 \cdot 2$ & 22 & Green & $p<0.05$ \\
\hline
\end{tabular}

$*=$ Brown $\times$ Green cross.

value. Heritability of sensitivity as it affects green pupal colouration was estimated from the green $\times$ green crosses using the equation:

$$
h^{2}=2 b=2\left(\frac{X_{g}-X_{r}}{a}\right)
$$

where $h^{2}$ is the heritability (additive genetic variance as a proportion of the phenotypic variance) and $b$ is the regression coefficient of parental on offspring values evaluated by subtracting the normal deviate (single tailed) of the per cent green pupae among progeny from the crosses $\left(X_{r}\right)$ from the normal deviate of the per cent green pupae in the $(S)$ line $\left(X_{g}\right)$ (table 1$)$, and dividing by $a=Z / C$ per cent green in (S), the mean deviation of (S) individuals (Falconer, 1965). The calculated heritability value, 1.42 \pm 0.96 (S.E.), exceeds the theoretical maximum of 1.0 , and has a large standard error.

\section{(ii) Diapause and pupal color}

A positive genetic correlation exists between sensitivity to colourinfluencing stimuli and CP. Within the (S) strain, brown pupae are 30-50 per cent more likely to diapause under LD 12:12 to LD 14:10 photoperiods and, at $23.5^{\circ} \mathrm{C}$, have a $\mathrm{CP}>1 \mathrm{hr}$ longer $(13.7 \mathrm{hr}$ vs. $12.5 \mathrm{hr})$, than 


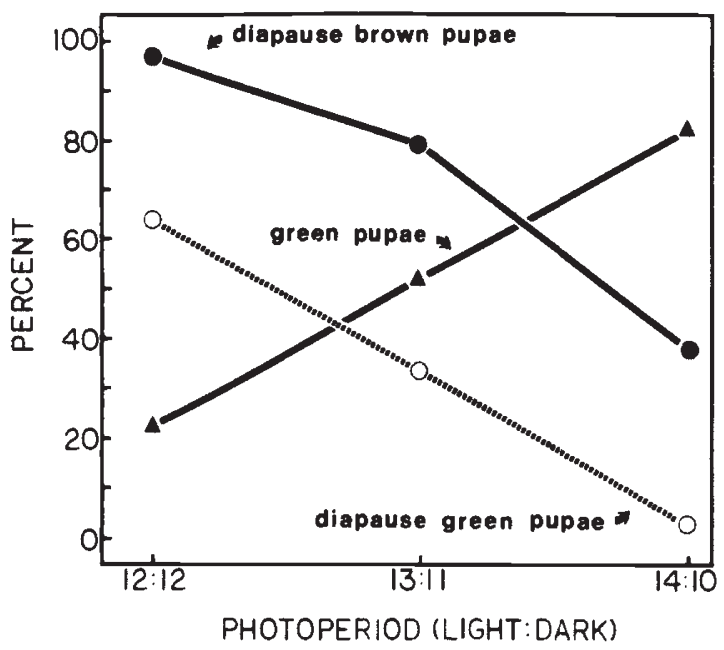

FIG. 2. Influence of rearing photoperiod $\left(@ 23 \cdot 5^{\circ} \mathrm{C}\right)$ on pupal colour and diapause of Papilio zelicaon.

green pupae (fig. 2). Populations such as (U) with the longest $\mathrm{CP}$ and most intense diapause have the highest incidence of brown pupae and greatest percentage of diapause in both colour forms (table 1).

Selection for reduced CP in the (S) line (Sims, in review) resulted in more green pupae, apparently due to lowered sensitivity, and less green and brown pupal diapause compared to the founder $(\mathbf{M})$ population (table 1). Crosses between the (U) and (S) lines produced hybrids with intermediate values of diapause brown and diapause green pupae but with a significant tendency to resemble the population response of the female parent.

TABLE 3

Effect of pupation substrate and larval rearing conditions on pupal color of Papilio zelicaon

\begin{tabular}{|c|c|c|c|c|c|c|}
\hline \multirow[b]{2}{*}{$\begin{array}{l}\text { Rearing } \\
\text { conditions }\end{array}$} & $\begin{array}{r}\text { Green } \\
(3=6\end{array}$ & $\begin{array}{l}\text { Pupati } \\
\text { twigs } \\
\text { mm) }\end{array}$ & $\begin{array}{l}\text { n Condition } \\
\text { White n } \\
\tan \text { wood ( }\end{array}$ & $\begin{array}{l}\text { ing and } \\
\text { mm wide) }\end{array}$ & \multirow{2}{*}{$\begin{array}{l}\text { Relative } \\
\% \text { increase } \\
\text { of brown } \\
\text { pupae on } \\
\text { net/wood }\end{array}$} & \multirow[b]{2}{*}{${ }^{\mathrm{a}} \chi^{2}$} \\
\hline & $\begin{array}{c}\% \text { Brown } \\
\text { pupae }\end{array}$ & $\begin{array}{l}\text { Sample } \\
\text { size }\end{array}$ & $\begin{array}{c}\% \text { Brown } \\
\text { pupae }\end{array}$ & $\begin{array}{l}\text { Sample } \\
\text { size }\end{array}$ & & \\
\hline $\begin{array}{l}\text { LD } 12: 12 \\
23 \cdot 5^{\circ}\end{array}$ & $73 \cdot 1$ & 167 & $84 \cdot 0$ & 312 & 11 & $8 \cdot 16^{* *}$ \\
\hline $\begin{array}{l}\text { LD } 13: 11 \\
23 \cdot 5^{\circ}\end{array}$ & $51 \cdot 5$ & 165 & $62 \cdot 5$ & 253 & 11 & $4.91^{*}$ \\
\hline $\begin{array}{l}\text { LD } 14: 10 \\
23 \cdot 5^{\circ}\end{array}$ & $10 \cdot 3$ & 116 & 39.7 & 501 & 30 & $36 \cdot 12^{* * *}$ \\
\hline $\begin{array}{l}\text { LD } 12: 12^{b} \\
29 \cdot 5^{\circ}\end{array}$ & $13 \cdot 0$ & 77 & $43 \cdot 2$ & 74 & 30 & $17 \cdot 21^{* * *}$ \\
\hline $\begin{array}{l}\text { LD } 18: 6^{b} \\
29 \cdot 5^{\circ}\end{array}$ & $13 \cdot 7$ & 95 & $59 \cdot 8$ & 102 & 46 & $44 \cdot 61^{* * *}$ \\
\hline
\end{tabular}

a *, $p<0.05 ; * *, p<0.01 ; * * *, p<0.001$.

${ }^{b}$ Reared in 2-litre white cardboard with white nylon netting on top. 


\section{(iii) Environmental effects on pupal colour dimorphism}

Pupal colouration in $P$. zelicaon is strongly influenced by both rearing conditions and pupation substrate. The incidence of green pupae increases with increasing photoperiod (fig. 2 , table 3$)$. Warm $\left(29.5^{\circ} \mathrm{C}\right)$ rearing conditions also induce high levels of green pupae, even at short photoperiods (table 3). Under given photoperiod/temperature conditions, pupal colouration is modified by qualities of the pupation substrate such as colour and perhaps width. Significantly more green pupae formed on narrow green twigs of the foodplant $(F$. vulgare) than on the white netting and tan wood (table 3). The relative difference between percent brown pupae formed on twigs vs. netting/wood was greatest under rearing conditions favoring continuous development, i.e., LD $14: 10,23 \cdot 5^{\circ} \mathrm{C}$; LD $12: 12$ and LD 18:6, $29.5^{\circ} \mathrm{C}$ (table 3 ). The effects of colour and width of the pupation substrate on pupal colour of $P$. zelicaon under long-days and warm temperatures are significantly, though incompletely, overridden by short-day cool conditions.

\section{Discussion}

The hypothesis that pupal colour dimorphism in $P$. zelicaon is a polygenic trait with a threshold effect is supported by the results of this study. The sensitivity level of progeny is a function of the midparent value and this level is reflected in the relative proportions of brown and green pupae per brood. Comparison of within-brood colour frequencies from different populations of $P$. zelicaon indicates that (1) significant variation occurs within and among broods reflecting quantitative genetic variation, (2) the mean sensitivity level of individual broods is normally distributed within populations, and (3) population differentiation in sensitivity exists. Hazel (1977) reached similar conclusions working with the related $P$. polyxenes. Rearing and pupation conditions clearly influence the threshold of sensitivity, mandating precise specification of these conditions when making interpopulation comparisons.

Both the positive response of pupal colour to selection and the heritability value indicate that substantial genetic variation underlies the sensitivity trait. A significant increase in brown pupae only occurred in a single cross where the parents and both parental broods were all green pupae. This somewhat anomalous result suggests that one or both parents were close to the brown sensitivity threshold. Heritability in this study is calculated in the broad sense, i.e., an estimate of the extent to which phenotypic variation of the pupal colour trait is due to genetic variation, combining additive, dominance, and interaction (=epistasis) effects. Because in the more rigorous sense, $h^{2}=V_{a} / V_{p}$, the ratio of additive to phenotypic variance, the result obtained here is probably an overestimate. Significant differences in sensitivity were found between the $(U)$ and $(M)$ populations with the (U) group having greater sensitivity (=more brown pupae). The (S) strain, derived from (M) and selected for low diapause incidence (Sims, in review) had lower sensitivity than the parent population. The intermediate colour frequency response of hybrids between (U) and (S) is consistent with the probable quantitative genetic control of sensitivity, however, the hypothesis that all the contributing loci are of equal effect may be untenable. 
Decrease in the sensitivity of the (S) strain accompanying selection for decreased diapause incidence plus inter- and intrapopulation differences in the percentage diapausing green and brown pupae strongly suggest a positive genetic correlation between brown pupal colouration (= sensitivity) and diapause. A spectrum of melanization intensity occurs in the brown pupal form. The amount of black pigment in the pupal cuticle is also correlated with the diapause state. Diapause brown pupae are usually a relatively unmelanized tan colour. Similarly, diapause green pupae are dull green or greenish-tan compared to the brighter apple green of nondiapausers. The populations (U) with the longest $\mathrm{CP}$ and greatest incidence of "obligate" and prolonged ( $\geqq 2$ years) diapause have the strongest sensitivity and thus the greatest incidence of brown pupae (Sims, 1980; table 1).

Pupal diapause in $P$. zelicaon is also a threshold trait with polygenic inheritance, modified by maternal effects, controlling the CP (Sims, in review). The maternal effects which modify diapause response are apparent in the percent diapause green and brown pupae of reciprocal hybrids as well. Thus, the correlated response between diapause and pupal colour is intermediate in hybrids but there is a significant tendency for hybrids to resemble the diapause-colour response of the female parent population.

A correlated response between diapause and pupal colour occurs in many papilionids from the temperate zone. The response may be complete as in $P$. polyxenes or $P$. xuthus such that all diapause pupae are brown or orange, respectively, or partial as in $P$. polytes or Battus philenor where more brown pupae diapause than green (Ishizaki, 1958; West, et al., 1972; Smith, 1978; Sims and Shapiro, 1983). The evolution of this response may have been facilitated by common elements of neuroendocrine control of both diapause (Beck, 1980) and pupal colour (Hidaka, 1961 $a$; Smith, 1978) and the selective advantage of a brown colour form that cryptically matches the predominant drab colours of the surrounding vegetation during the winter diapause period (Wiklund, 1975; West and Hazel, 1982). The influence of substrate quality on $P$. zelicaon pupal colour (i.e., green pupae on narrow green twigs, brown pupae on wide substrates of non-green colour) is also similar to that found in other swallowtail species (West, et al., 1972; Gardiner, 1974; Smith, 1978; Sims and Shapiro, 1983). Both the influence of substrate quality on pupal colour and the correlation between sensitivity and $\mathrm{CP}$ suggest predator selection for cryptic pupae. The magnitude of the sensitivity-CP correlation may reflect the intensity of selection pressure exerted on noncryptic pupae during diapause. Hazel (1977) speculated that the strong effect of photoperiod on dimorphism is a trait associated with multivoltinism and that this possibly originated from the comparative advantage of a single colour form in the relatively short diapause period of multivoltine species.

Although photoperiod and diapause exert a predominant influence on pupal colouration of $P$. zelicaon, this control is incomplete. The underlying genetic variance in sensitivity and incomplete correlation between brown colour and diapause permits a relatively large number of apparent noncryptic "mistakes". For example, many brown pupae are found on narrow green substrates, and green pupae often diapause. In this study, 16 per cent of pupae were green on brown-promoting substrates under short days, while 10-14 per cent of pupae on green twigs under long days were brown. These individuals occur in the tails of the sensitivity distribution and 
represent genotypes most refractory to environmental stimulation. Their existence suggests the following question: what selective factors influence the mean level of sensitivity in a population and the correlation between sensitivity and diapause, pupation site-selection behavior or other traits? The structure of the pupation habitat and the predator species composition and density are of obvious importance (Wiklund, 1975; West and Hazel, 1982) and are subject to seasonal and between-habitat variation. Sensitivity should be adjusted by the relative disadvantage of green pupae on brown backgrounds versus the disadvantage of brown pupae on green backgrounds (Clarke and Sheppard, 1972). Wiklund (1975) for example, found that the relative selective advantage of cryptic green pupae was 5-7 times greater than non-cryptic brown, while cryptic brown pupae had only a 2-3 times advantage over non-cryptic green. Such a population would be expected to achieve and maintain a relatively insensitive response to substrate colour. Apostatic (frequency-dependent) selection due to predator formation of searching images represents another potential short-term influence on population sensitivity by favoring the rarer of the two colour morphs (Clarke, 1969; Allen, 1976). The relative frequency and conspicuousness of the colour forms would influence the degree of apostatic selection. In addition to apostatic selection, variation in levels of predation pressure both within year (between generation) (Wiklund, 1975) and between years (West and Hazel, 1982) probably causes fluctuation in population sensitivity levels.

Finally, the threshold nature of the pupal colour trait presumably moderates the effects of selection and maintains variation in sensitivity. Under a given set of environmental conditions, individuals with a wide range of sensitivities (i.e., all those either above or below the threshold) will achieve cryptic colouration. Selection is facilitated if the incidence of a colour form is equal to the proportion of all pupae surviving predation (Falconer, 1960). This condition seems quite unlikely in the spatially and temporally heterogeneous habitats occupied by $P$. zelicaon.

Acknowledgements. Thanks are due to F. Gould, M. Tafar, and A. M. Shapiro for reviews of this work.

\section{REFERENCES}

ALLEN, J. A. 1976. Further evidence for apostatic selection by wild passerine birds-9:1 experiments. Heredity, 36, 173-180.

BECK, S, D. 1980. Insect Photoperiodism. Second edition, Academic Press, New York.

CLARKE, B. 1969. The evidence for apostatic selection. Heredity, 24, 347-352.

ClARKe, C. A. 1952. Pupal coloration in Papilio machaon Linn. Proc. and Trans. South Lond. Entomol. and Nat. Hist. Soc., 1952/53, 100-103.

ClARKE, C. A. AND ShePpARD, P. M. 1956. Hand pairing of butterflies. Lepid. News, 10, 47-53.

CLARKE, C. A. AND SHEPPARD, P. M. 1972. Genetic and environmental factors influencing pupal colour in the swallowtail butterfies Battus philenor (L.) and Papilio polytes L. J. Entomol. $(A), 46,123-133$.

FALCONER, D. S. 1960. Introduction to Quantitative Genetics. Ronald Press, New York.

FALCONER, D. S. 1965. The inheritance of liability to certain diseases, estimated from the incidence among relatives. Ann. Hum. Genet., 29, 51-76.

FUZEAU-BRAESCH, S. 1960 . Etude biologique et biochimique de la pigmentation d'un insecte: Gryllus bimaculatus. Bull. Biol. Fr. Belg., 94, 527-627. 
GARDINER, B. O. C. 1974. Observations on green pupae in Papilio machaon L. and Pieris brassicae L. Wilhelm Roux Archiv., 196, 13-22.

HAZEL, W. N. 1977. The genetic basis of pupal colour dimorphism and its maintenance by natural selection in Papilio polyxenes (Papilionidae: Lepidoptera). Heredity, 38, 227-236.

HAZEL, W. N. AND WEST, D. A. 1979. Environmental control of pupal colour in swallowtail butterflies (Lepidoptera: Papilioninae): Battus philenor (L.) and Papilio polyxenes Fabr. Ecol. Entomol., 4, 393-400.

HIDAKA, T. 1961 $a$. Mise en evidence de l'activité sécrétoire du ganglion prothoracique dans l'adaptation de la nymphe du Papilio xuthus L. C. r. Soc. Biol. Paris, 154, 1682-1685.

HIDAKA, T. $1961 b$. Recherches sur le mécanisme endocrine de l'adaptation chromatique morphologique chez les nymphes de Papilio xuthus L. Tokyo Daigaku. Rigabuky (J. Fac. Sci. Imp. Univ. Tokyo), Sect. IV, 9, 223-261.

HONDA, K. 1979. Environmental factors affecting the pupal coloration in Papilio protenor demetrius Cr. (Lepidoptera: Papilionidae) I. Effect of chemical stimulus (Odor). Kontyu, 47, 191-195.

HONDA, K. 1981. Environmental factors affecting the pupal coloration in Papilio protenor demetrius Cr. (Lepidoptera: Papilionidae) II. Effect of physical stimuli. Appl. Entomol. Zool., 16, 467-471.

ISHIZAKI, H. 1958. Correlation between colour variation and diapause in the pupa of swallow tail, Papilio xuthus. Seiri-Seitai (Kyoto Univ., Faculty of Science, Zool. Lab.), 8, 32-35.

ISHIZAKI, H. AND KATO, M. 1956. Environmental factors affecting the formation of orange pupa in Papilio xuthus. Mem. Coll. Sci., Univ. Kyoto (B), 23, 11-18.

MOSTELLER, F. AND YOUTZ, C. 1961. Tables of the Freeman-Tukey transformations for the binomial and poisson distributions. Biometrika, 48, 433-440.

NEL, D. 1968. Selection at a high humidity for green and brown solitaria hopper coloration in Locustana pardalina. S. Afr. J. Agr. Sci., 11, 163-172.

OHNISHI, E. AND HIDAKA, T. 1956. Effect of environmental factors on the determination of pupal types in some swallowtails, Papilio xuthus L. and $P$. protenor demetrius $\mathrm{Cr}$. Dobutsugaku Zasshi, 65, 185-187.

SIMS, S. R. 1980. Diapause dynamics and host plant suitability of Papilio zelicaon (Lepidoptera: Papilionidae). Amer. Midl. Nat., 103, 375-384.

SIMS, S. R. AND SHAPIRO, A. M. 1983. Pupal color dimorphism in California Battus philenor (L.): Pupation sites, environmental control, and diapause linkage. Ecol. Entomol. (in press).

SIMS, S. R. (In review). Inheritance of diapause induction and intensity in Papilio zelicaon. Heredity.

SMITH, A. G. 1978. Environmental factors influencing pupal colour determination in Lepidoptera. I. Experiments with Papilio polytes, Papilio demoleus and Papilio polyxenes, Proc. R. Soc. Lond. B., 200, 295-329.

SMITH, A. G. 1980. Environmental factors influencing pupal colour determination in Lepidoptera. II. Experiments with Pieris rapae, Pieris napi, and Pieris brassicae. Proc. $R$. Soc. Lond. B., 207, 163-186.

SOKAL, R. R. AND ROHLF, F. J. 1969. Biometry. W. H. Freeman, San Francisco.

WEST, D. A. AND HAZEL, W. N. 1979. Natural pupation sites of swallowtail butterflies (Lepidoptera: Papilioninae): Papilio polyxenes Fabr., P. glaucus L., and Battus philenor (L.). Ecol. Entomol., 4, 387-392.

WEST, D. A. AND HAZEL, W. N. 1982. An experimental test of natural selection for pupation site in swallowtail butterflies. Evolution, 36, 152-159.

WEST, D. A., SNEllings, W. M. AND HerbeK, T. A. 1972. Pupal color dimorphism and its environmental control in Papilio polyxenes asterius (Lepidoptera: Papilionidae). J. New York Entomol. Soc., 80, 205-211.

WIKLUND, C. 1972. Pupal coloration in Papilio machaon in response to wavelength of light. Naturwissenschaften, 59, 219.

WIKLUND, C. 1975. Pupal colour polymorphism and the survival in the field of cryptic versus non-cryptic pupae in Papilio machaon L. J. Roy. Entomol. Soc. Lond., 127, 73-84. 